\title{
MECHANICAL CAVITY DESIGN FOR 100MV UPGRADE CRYOMODULE*
}

K. M. Wilson ${ }^{\dagger}$, G. Ciovati, E. F. Daly, J. Henry, R. Hicks, J. Hogan, D. Machie, P. Kneisel, C. Reece, J. Sekutowicz, T. Whitlatch, Thomas Jefferson National Accelerator Facility, Newport

News, VA 23606

\section{Abstract}

To achieve up to $6 \mathrm{GeV}$, each cryomodule in the CEBAF accelerator currently provides about $30 \mathrm{MV}$ of acceleration. To raise the accelerator energy to $12 \mathrm{GeV}$, ten additional cryomodules capable of providing over 100 MV of acceleration are required. A prototype of the 100 MV cryomodule has been designed, is presently under construction, and will be completed in 2004. This prototype cryomodule comprises two new cavity designs, four cavities of the low loss design and four cavities of the high gradient design.

Although the cavity shapes were designed for their RF properties, the mechanical implications must be considered. In addition to the new cavity shapes, changes have also been made to the cavity end dish assemblies, weld joints, and stiffening rings. This paper will present the results of the stress and vibration analyses used for designing the cryomodule.

\section{STRESS ANALYSIS}

Two critical load cases were examined, one for the warm cavities and one for the cold. The highest stresses in the cold cavity will result from the superposition of tuning and pressure loads. The cavity may be displaced by as much as $2 \mathrm{~mm}$ during tuning; in theory, this could coincide with a pressure load of up to 4 atm in case of system failure. For the warm cavity, the greatest stresses will most likely occur during alignment. The cavities are held just outside the end cells and force is applied to the beampipe flange to bring the beampipe into alignment for assembly.

\section{Model Description}

During the course of the cavity design, several different configurations were considered and analyzed for both the low-loss and high-gradient cavities. Figure 1 reflects the final design of the low-loss cavity.

For the analysis of the cold cavity, a two-dimensional part was meshed with axisymmetric parabolic elements. As shown in Figure 1, blue elements are titanium, red elements are niobium-titanium, and green elements are niobium.

For the warm analysis, only the beampipe was modeled (Figure 4) since it was assumed the cavity would be fully fixed just outside the cells and only the beam pipe would deform. A half-model was used and meshed with parabolic solid elements.

\footnotetext{
* Supported by US DOE Contract No. DE-AC05-84ER40150

"kwilson@jlab.org
}

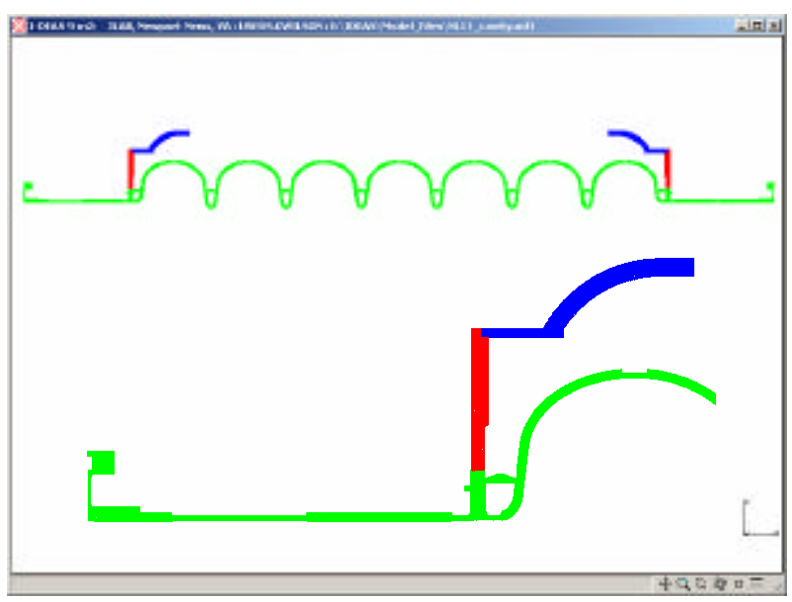

Figure 1: Low loss cavity mesh

\section{Material Properties}

Material properties used in the model are shown in the tables below.

Table 1: Material Properties of Niobium ${ }^{1,2}$

\begin{tabular}{|l|c|c|}
\hline \multicolumn{1}{|c|}{ Property } & SI Units & English Units \\
\hline \hline $\begin{array}{l}\text { Modulus - } \\
\text { Room Temp }\end{array}$ & $1.03 \mathrm{E}+11 \mathrm{~Pa}$ & $1.49 \mathrm{E}+07 \mathrm{psi}$ \\
\hline $\begin{array}{l}\text { Modulus - } \\
\text { Cryo Temp }\end{array}$ & $1.23 \mathrm{E}+11 \mathrm{~Pa}$ & $1.79 \mathrm{E}+07 \mathrm{psi}$ \\
\hline $\begin{array}{l}\text { Poisson's } \\
\text { Ratio }\end{array}$ & \multicolumn{2}{|c|}{0.38} \\
\hline Density & $\begin{array}{c}8.58 \mathrm{E}-03 \\
\mathrm{~g} / \mathrm{mm}^{3}\end{array}$ & $\begin{array}{c}0.31 \\
\mathrm{lb}^{3} \mathrm{in}^{3}\end{array}$ \\
\hline Yield - RT & $4.83 \mathrm{E}+07 \mathrm{~Pa}$ & $7.0 \mathrm{ksi}^{3}$ \\
\hline Yield - Cryo & $5.77 \mathrm{E}+08 \mathrm{~Pa}$ & $83.7 \mathrm{ks}^{4}$ \\
\hline
\end{tabular}

Table 2: Material Properties of Titanium ${ }^{5}$

\begin{tabular}{|l|c|c|}
\hline \multicolumn{1}{|c|}{ Property } & SI Units & English Units \\
\hline \hline $\begin{array}{l}\text { Modulus - } \\
\text { Room Temp }\end{array}$ & $1.02 \mathrm{E}+11 \mathrm{~Pa}$ & $1.48 \mathrm{E}+07 \mathrm{psi}$ \\
\hline $\begin{array}{l}\text { Modulus - } \\
\text { Cryo Temp }\end{array}$ & $1.25 \mathrm{E}+11 \mathrm{~Pa}$ & $1.81 \mathrm{E}+07 \mathrm{psi}$ \\
\hline $\begin{array}{l}\text { Poisson's } \\
\text { Ratio - RT }\end{array}$ & \multicolumn{2}{|c|}{0.338} \\
\hline $\begin{array}{l}\text { Poisson's } \\
\text { Ratio - Cryo }\end{array}$ & \multicolumn{2}{|c|}{0.305} \\
\hline Density & $\begin{array}{c}4.51 \mathrm{E}-03 \\
\mathrm{~g} / \mathrm{mm}^{3}\end{array}$ & 0.163 \\
& $\mathrm{lb} / \mathrm{in}^{3}$ \\
\hline
\end{tabular}

In the absence of data on the cryogenic properties of niobium-titanium, an assumption was made that the 
modulus would follow the same trend as niobium and titanium and increase by about $21 \%$ over the room temperature modulus.

Table 3: Material Properties of Niobium-Titanium

\begin{tabular}{|l|c|c|}
\hline \multicolumn{1}{|c|}{ Property } & SI Units & English Units \\
\hline \hline $\begin{array}{l}\text { Modulus - } \\
\text { Room Temp }\end{array}$ & $7.31 \mathrm{E}+10 \mathrm{~Pa}$ & $1.06 \mathrm{E}+07 \mathrm{psi}$ \\
\hline $\begin{array}{l}\text { Modulus - } \\
\text { Cryo Temp }\end{array}$ & $8.83 \mathrm{E}+10 \mathrm{~Pa}$ & $1.28 \mathrm{E}+07 \mathrm{psi}$ \\
\hline $\begin{array}{l}\text { Poisson's } \\
\text { Ratio }\end{array}$ & \multicolumn{2}{|c|}{0.38} \\
\hline Density & $\begin{array}{c}6.36 \mathrm{E}-03 \\
\mathrm{~g} / \mathrm{mm}^{3}\end{array}$ & 0.23 \\
& $\mathrm{lb} / \mathrm{in}^{3}$ \\
\hline
\end{tabular}

\section{Boundary Conditions}

For the cold cavity, a $2 \mathrm{~mm}$ outwards deflection was applied to one of the dished heads on the cavity model, representing the maximum displacement during cavity tuning. In addition, a 4-atmosphere pressure load, the maximum failure load the cavity could experience, was applied to the outside of the cavity; the operational pressure load is only 0.034 atmosphere. The cavity was allowed to move freely in the axial direction.



Figure 2: Loads on cold cavity

For the warm cavity, the primary concern was stresses from alignment. The half model was restrained in its plane of symmetry and fixed at the end adjacent to the cavity. The beampipe flange was displaced vertically 1.5 $\mathrm{mm}$ and rotated slightly as indicated by the arrows in Figure 4. This was the maximum estimated displacement of the flange during alignment.

\section{Results}

On the cold cavity, the greatest stress is at the intersection of the stiffener and the end cell, as shown in Figure 3. The yield strength of niobium under cryogenic conditions is about $84 \mathrm{ksi}$. The maximum Von Mises stresses in this area are under $20 \mathrm{ksi}$.

For the warm cavity, the maximum alignment stresses occur in the flange at the end of the beam pipe. Since the

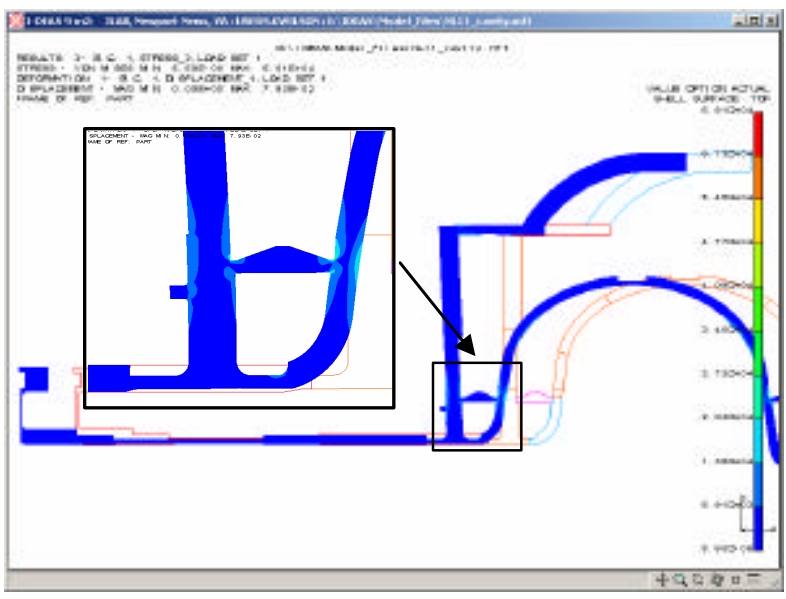

Figure 3: Low Loss $-2 \mathrm{~mm}$ deflection +4 atm load

analysis involves plastic deformation of the material, Figure 4 shows the strains, which are proportional to the deflection, rather than the stresses, which are dependent on the stress-strain graph of the particular material. The ultimate tensile strength of niobium is much smaller warm than cold, about $20 \mathrm{ksi}^{6}$ The stress-strain properties of this particular material are still being investigated. Graphs of typical niobium properties show that, for the worst case material located, failure would occur at 0.026 in/in of strain. With the given deflections, the greatest strains in cavity beampipe are about 0.007 in/in.

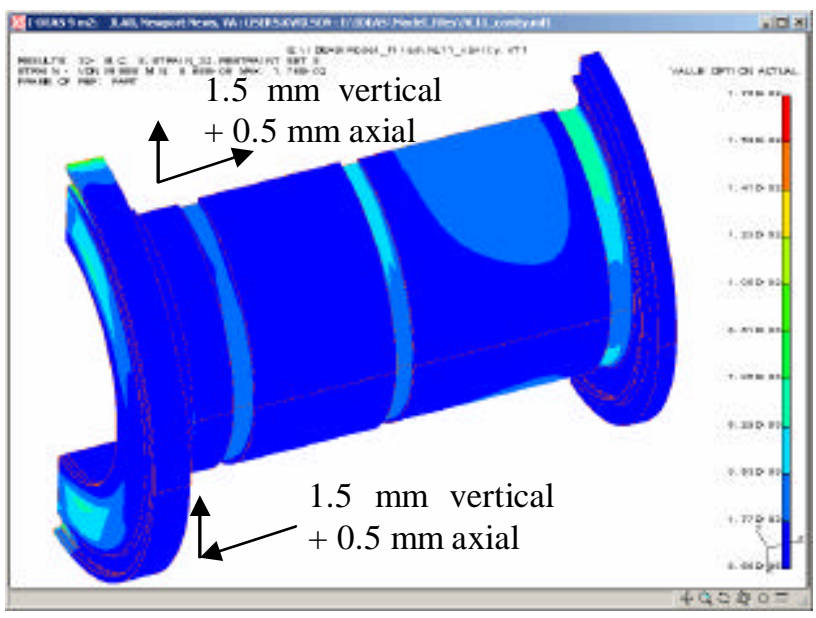

Figure 4: Alignment strains

\section{NORMAL MODES ANALYSIS}

\section{Model Description}

Both the high gradient and low loss cavities consist of seven cells with stiffeners between them. Additional stiffeners connect the end cells to the end dishes on each end. At both the axis and equator of each cell, weld preps result in somewhat thinner material, and this was included in the model.

A full three-dimensional model of the cavities only (without beampipes) was meshed with parabolic shell elements. Elements shown in green are niobium and elements in red are the niobium-titanium end dishes. 
The material properties used are shown in Tables 1 and 3 , above.

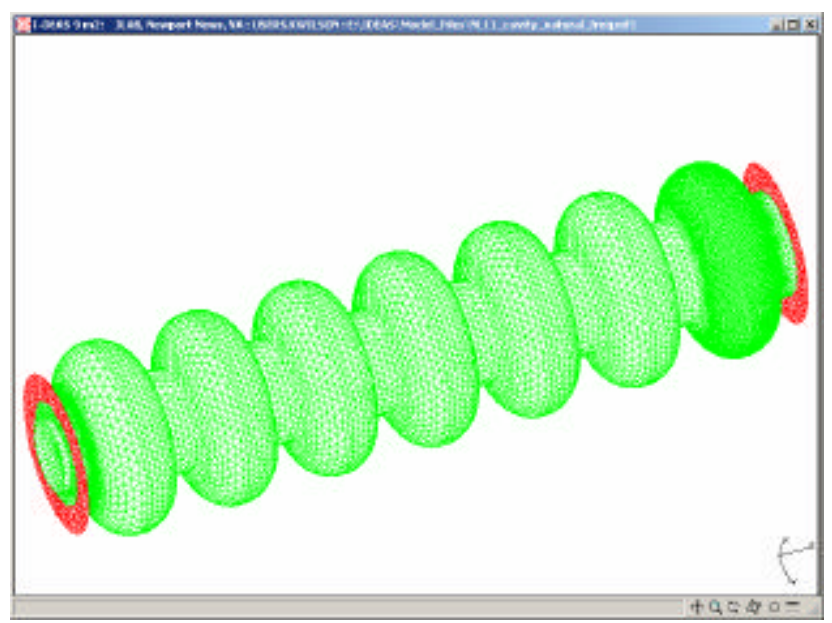

Figure 5: Shell mesh on high gradient cavity

\section{Boundary Conditions}

The stiffnesses of both the high gradient and low loss cavities were determined, using both room temperature and cryogenic material properties, to verify that these correlate with the natural frequencies. A nominal load of $100 \mathrm{lbf}$ was applied to one end of the cavities and the other was held fixed to determine the resulting deflection. The spring constant was calculated from this.

The fundamental frequencies of the cavities was then determined with both ends fully fixed.

\section{Results}

The cavity stiffnesses, shown in Table 4, are more strongly influenced by the temperature of the cavities than by the difference in shape between the high gradient and low loss cavities.

Table 4: Cavity Spring Constants (lb/in)

\begin{tabular}{|l|c|r|}
\hline & Room Temp. & Cryogenic \\
\hline High Gradient & 32,400 & 38,900 \\
\hline Low Loss & 32,500 & 39,000 \\
\hline
\end{tabular}

The fundamental frequencies of the cavities are shown in Table 5. The second and third bending modes are significantly higher, as expected; for a beam, the natural frequency of the second bending mode is nearly three times higher than the first mode and the third mode is about five times higher. These are shown in Table 6.

Table 5: Cavity Frequencies, First Mode (Hz)

\begin{tabular}{|l|r|r|}
\hline & Room temp & Cryogenic \\
\hline High Gradient & 114 & 125 \\
\hline Low Loss & 112 & 123 \\
\hline
\end{tabular}

In addition, an axial mode exists between the second and third bending modes.

Table 6: High Gradient Cavity Frequencies (Hz)

\begin{tabular}{|l|r|r|}
\hline & Second Mode & \multicolumn{1}{l|}{ Third Mode } \\
\hline Room Temperature & 285 & 494 \\
\hline Cryogenic & 312 & 541 \\
\hline
\end{tabular}

For comparison, hand calculations (assuming the cavity can be treated like a beam) for the high gradient cavity at room temperature give the first three bending modes as 99, 270, and $530 \mathrm{~Hz}$.

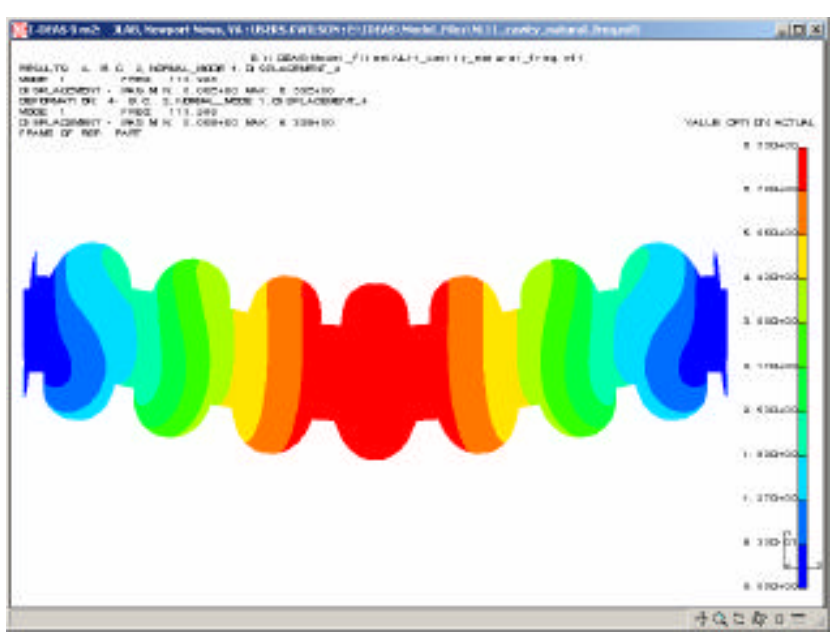

Figure 6: Fundamental frequency of high gradient cavity

\section{CONCLUSIONS}

The current cavity design meets stress and frequency requirements, and manufacturing of the prototypes is underway.

Efforts to verify these analyses experimentally are ongoing. Work with other cavities suggests that alignment within these limits will not damage the cavities and has a minimal effect on field flatness. Tests of the cavity stiffnesses and natural frequencies are currently being performed on a prototype high gradient cavity.

Plans for future analyses include a study of the effects of Lorenz force detuning.

\section{REFERENCES}

[1] Mark Wiseman, "Normal Mode Analysis of the CEBAF Accelerator Cavity." TN-89-144, dated 7/17/89.

[2] Metals Handbook, $10^{\text {th }}$ Ed., Vol. 2. (USA: ASM International, 1990): 1144-1145.

[3] Technical Specification for Niobium for Use in Superconducting Accelerators (RRR Grade). Specification 11111SO144, Rev. 7. 1 October 1999

[4] Peter Kneisel and Ganapati Rao Myneni, "Preliminary Results of Tensile Test on Niobium at Room Temperature and 4.2K." TN-88-097. (October 1988): Table 2.

[5] Email from Russ Mitchell to Katherine Wilson dated 6 December 2002

[6] Ganapati Myneni and Peter Kneisel, "High RRR Niobium Material Studies" TN-02-01. 